\title{
Extract Ethyl Acetate Red Fruit (Pandanus Conoideus Lam.) as a Counterstain in Gram Staining Technique
}

\author{
Warta Dewi ${ }^{1}$, Indrati1 ${ }^{1}$ Inne Suherna Sasmita ${ }^{2}$
}

\author{
${ }^{1}$ Department of Oral Biology, Faculty of Dentistry Padjadjaran University \\ ${ }^{2}$ Departement of Pediatric Dentistry, Faculty of Dentistry Padjadjaran University, Bandung, West Java, Indonesia
}

\begin{abstract}
Objective: to test the extract of ethyl acetate Red Fruit (Pandanus Conoideus Lam.) As dye substitution in Gram staining technique. Material and Methods: Made Preparations from the suspension Escherichia coli ATCC 25922 and Streptococcus sanguine ATCC 10556 counted 30 preparation, and then done Gram staining process to this preparation. 1 preparation using counterstain basic fuchsin as a control and 29 other preparations using ethyl acetate extract of Red Fruit as a counterstain, the result of staining compared to using standard degradation of RHS color chart. Result: From 29 sample preparations used the counterstain extract of ethyl acetate Red Fruit (Pandanus Conoideus Lam.), 12 preparations produced a color close to color code 62B on the standard degradation of RHS color chart that is moderate purplish pink. Conclusions: From this preliminary study that examined the extract of ethyl acetate Red Fruit as a counterstain on Gram staining resulted in a color contrast between Gram + and Gram bacteria though not as good as if using compressed/counterstain basic fuchsin.
\end{abstract}

Keywords: Red fruit (Pandanus Conoidenus Lam.), Counterstain, Gram Staining Technique

\begin{abstract}
Introduction
Microbiology is one of the basic branches of medical science (Basic Medical Science) who studied the life of microorganisms are bacteria that can cause disease in humans and animals. Bacteria have unique characteristics both of shape, size, and formation. This characteristic can be seen through microscope examination, but the size of bacteria is very small that is about $0,2 \mu \mathrm{m}-0,5 \mu \mathrm{m}$ and transparant, so to be able to see bacteria under microscope need to be done the process of putting dye into the body of bacteria called by the process of staining Bacterial. Bacteria do not absorb or refract light, this is why bacteria are difficult to see with a direct light microscope. Therefore, it is necessary to dye to color the microorganisms, this dye is able to absorb and refract light. The combination of microscopic lighting and coloring processes became one of the most important procedures in the field of microbiology to study the nature of bacteria and group them into more specific groups. $^{1,2,3}$
\end{abstract}

Bacteria staining process can be done by using one kind of dye which is referred to as Simple Staining and two kinds of dyes called Differential staining as an example is the Gram stain.,

Through microscopic examination of bacteria that have been colored can be seen morphology of shape, size, formation and its nature. Is it Gram + (purple) or Gram - (pink / red). ${ }^{3}$ Microscopic examination is an important step in the process of a bacteriological diagnosis which is a step / initial step for diagnosing the disease in humans and animals.

Bacterial staining methods used until now still use dyes synthetic chemicals that are quite expensive as carbolic Gentian Violet, Basic Fuchsin, safranin, Methylene Blue, Malachite Green and others. ${ }^{1,2}$

Indonesia as an agricultural country is very rich in its natural resources including its agricultural products. Eastern part of Indonesia (Papua) there are quite abundant agricultural products namely Red Fruit (Pandanus conoideus Lam.) Were utilized and consumed by the people of Papua as a source of food as well as food coloring agents. The content of beta carotene from this fruit causes the red color, carotenoids contained therein have been utilized by

This article is published under the terms of the Creative Commons Attribution License 4.0

Author(s) retain the copyright of this article. Publication rights with Alkhaer Publications.

Published at: http://www.ijsciences.com/pub/issue/2017-07/

DOI: 10.18483/ijSci.1357; Online ISSN: 2305-3925; Print ISSN: 2410-4477 
the people of Papua as a natural food coloring good. ${ }^{4.5}$

On the basis of this reason, the authors are interested in conducting preliminary research on Red Fruit to be used as a substitute of natural dyes from herbs to the process of bacterial staining.

\section{Materials and Methods}

The materials used to make this preliminary study are synthetic ingredients or chemical staining for Gram as carbolic Gentian Violet, Basic Fuchsin, Iodine, Alcohol $96 \%$ and ethyl acetate extract of red fruit in the form of a standard solution. For the test microorganisms used in this preliminary study is Escherichia coli ATCC 25922 and Streptococcus sanguis ATCC 10556.

The method of staining bacteria used is the Gram staining method. The procedure of making red fruit extract with the solvent ethyl acetate is as follows:

1. Red Fruit prepared approximately 150 grams then dried in the open air and cut into pieces as small as possible.

2. Then extracted by maceration using ethyl acetate solvent $1500 \mathrm{ml}$ with ratio 1:10. This maceration is carried out for 24 hours at room temperature.

3. Then filtration is done to obtain filtrate by using filter paper.

4. The obtained filtrate is then concentrated by evaporation using a rotary vacuum evaporator at a temperature of $45^{\circ}-50^{\circ} \mathrm{C}$ until a thickened filtrate is obtained. Furthermore, the extract is inserted into a sterile bottle.

5. Then dried with freeze dryer process to remove remaining residual solvent then extract is stored in the freezer.

6. This stage will produce ethyl acetate extract of Red Fruit with $100 \%$ concentration.

7. Next step is to prepare the preparation of dye extract ethyl acetate Red Fruit. The procedures performed are as follows: (1) Take 10 grams of ethyl acetate extract of Red Fruit; (2) Mix into $100 \mathrm{ml}$ of $96 \%$ alcohol, stir until homogeneous. This solution is a standard solution of ethyl acetate dye extract of Red Fruit.

Preparations of the second test microorganism is Escherichia coli ATCC 25922 and Streptococcus sanguis ATCC 10556 were mixed and made in the form of a suspension. From this suspension made a thin film above the glass object is dried and done fixation of preparations made as many as 30 pieces.
One gram staining preparations done by using carbolic Gentian Violet dye as a primary color agent has then used iodine (potassium iodide) as the mordant, decolorize with alcohol $96 \%$ and given the basic fuchsin counterstain. Gram staining results of these preparations are used as controls. For 29 other preparations done by replacing counterstain Gram with ethyl acetate extract of red fruit, this work is done as much as $2 \mathrm{x}$ repetition. ${ }^{1,2}$

\section{Results}

Results ethyl acetate extracts were prepared by maceration for 24 hours at room temperature after filtration and evaporation using a rotary vacuum evaporator make the solution viscous and red like the picture below.

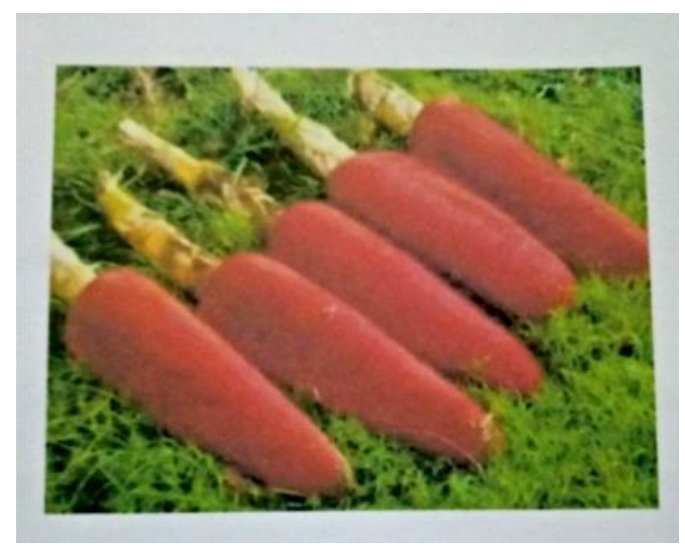

Figure 1. Red Fruit (Pandanus Conoideus Lam. $)^{6}$

Source :https://www.buahmerah.org/wpconten/uploads/2016/03/Buah-Merah-Papua-.jpg

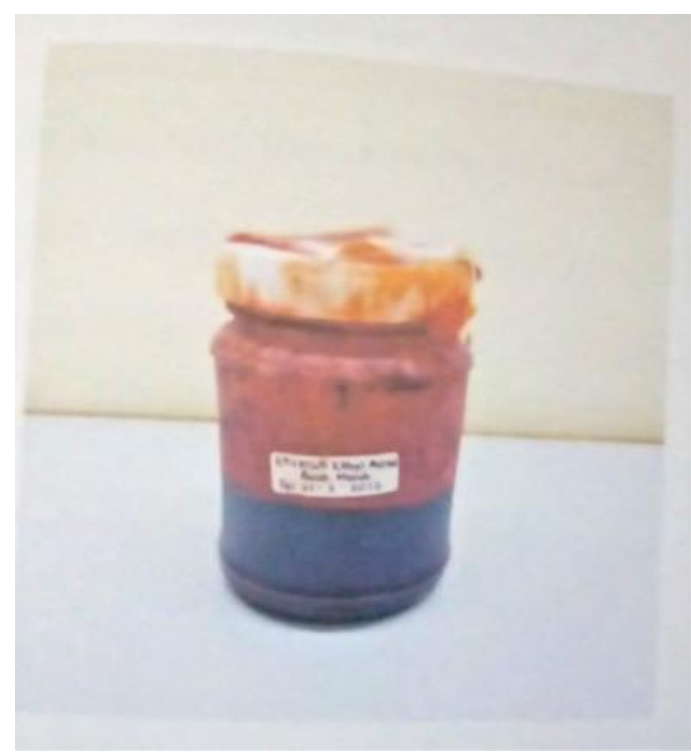

Figure 2. Red Fruit Extract Ethyl Acetate 
The resulting color of ethyl acetate extract of red fruit than the color of basic fuchsin looks like the image below.

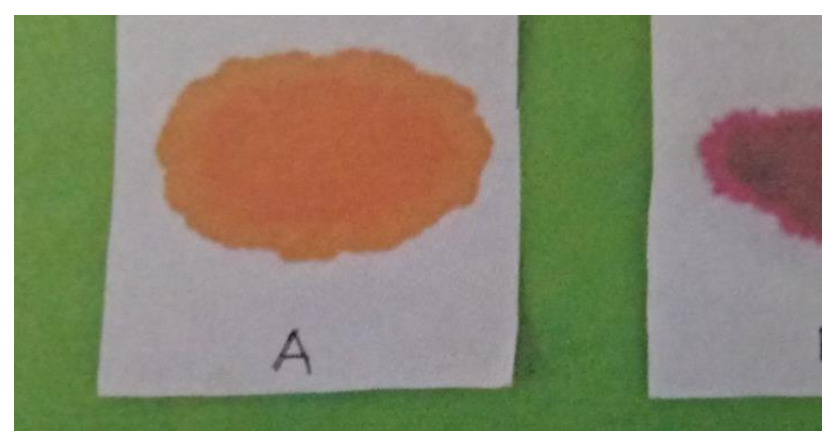

Figure 3. Color Comparison

\section{(A) Of Ethyl Acetate Extract Red Fruit (B) Basic Fuchsin}

Results Gram of the 30 preparations were stained with basic fuchsin as a control and the other 29 were stained with counterstain ethyl acetate extract of red fruit will be compared with the degradation table by the RHS Color Chart color as seen in the table below.

Table 1. Degradation of Color Based on the RHS Color Chart ${ }^{7}$

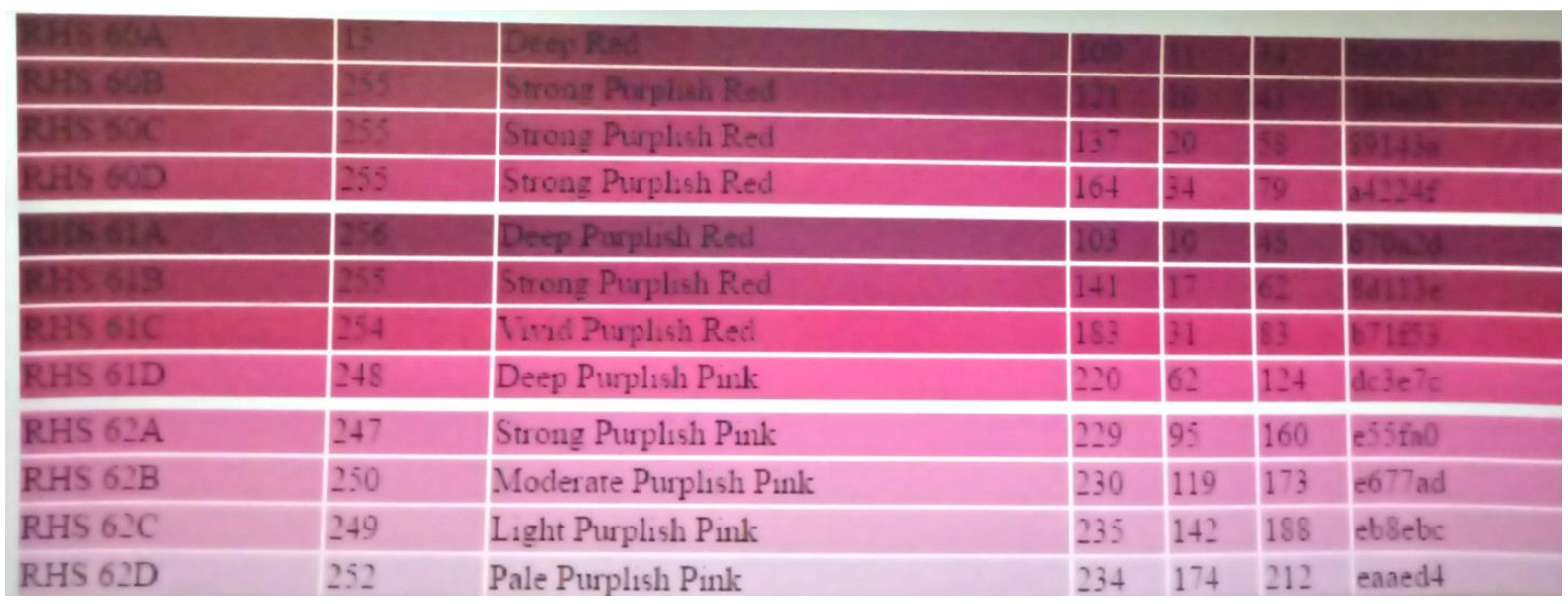

Results Gram at 1 preparations that use colored dyes comparator (basic fuchsin counterstain) and 29 other preparations by comparison dye (counterstain ethyl acetate extract of red fruit) (Pandanus conoideus Lam.) With 2x repetition can be seen in Table. 2 below.

Table 2. Preliminary Results Gram With Comparative Dye (counterstain) Ethyl Acetate Extract Red Fruit (Pandanus conoideus Lam.)

\begin{tabular}{|c|c|c|}
\hline $\begin{array}{c}\text { Preparations } \\
\text { Number }\end{array}$ & $\begin{array}{c}\text { Color Code In accordance with RHS Color } \\
\text { Chart Degradation }\end{array}$ & Description of color code \\
\hline 1 & $60 \mathrm{C}$ & Strong purplish red/ control \\
\hline 2 & $62 \mathrm{C}$ & Light purplish pink \\
\hline 3 & $62 \mathrm{C}$ & Light purplish pink \\
\hline 4 & $62 \mathrm{D}$ & Pale purplish pink \\
\hline 5 & - & Not colored \\
\hline 6 & $62 \mathrm{~B}$ & Noderate purplish pink \\
\hline 7 & $62 \mathrm{D}$ & Modered purplish pink \\
\hline 8 & - & Moderate purplish pink \\
\hline 9 & $62 \mathrm{~B}$ & Pale purplish pink \\
\hline 10 & $62 \mathrm{~B}$ & Not colored \\
\hline 11 & $62 \mathrm{D}$ & Not colored \\
\hline 12 & - & Pale purplish pink \\
\hline 13 & - & Moderate purplish pink \\
\hline 14 & $62 \mathrm{D}$ & \\
\hline
\end{tabular}




\begin{tabular}{|c|c|c|}
\hline 15 & $62 \mathrm{~B}$ & Moderate purplish pink \\
\hline 16 & $62 \mathrm{~B}$ & Moderate purplish pink \\
\hline 17 & $62 \mathrm{~B}$ & Moderate purplish pink \\
\hline 18 & $62 \mathrm{~B}$ & Moderate purplish pink \\
\hline 19 & $62 \mathrm{~B}$ & Moderate purplish pink \\
\hline 20 & $62 \mathrm{~B}$ & Pale purplish pink \\
\hline 21 & $62 \mathrm{D}$ & Not colored \\
\hline 22 & - & Light purplish pink \\
\hline 23 & $62 \mathrm{C}$ & Not colored \\
\hline 24 & - & Moderate purplish pink \\
\hline 25 & $62 \mathrm{~B}$ & Pale purplish pink \\
\hline 26 & $62 \mathrm{D}$ & Light purplish pink \\
\hline 27 & $62 \mathrm{C}$ & Pale purplish pink \\
\hline 28 & $62 \mathrm{D}$ & Moderate purplish pink \\
\hline 29 & $62 \mathrm{~B}$ & Moderate purplish pink \\
\hline 30 & $62 \mathrm{~B}$ & Not colored \\
\hline
\end{tabular}

Preparations using the basic fuchsin dye as the counterstain were used as controls in this study and after adjusting for the color degradation table/RHS Color Chart for Gram-Gram bacteria approaching 60C (strong purplish red) code. Based on the results that can be seen in the table. 2 shows that dye solution of ethyl acetate extract of Red Fruit used in Gram staining produces several colors that almost resemble basic fuchsin. The overall results obtained were 4 color-coded 62C (light purplish pink) preparations, 7 preparations approaching the color code of $62 \mathrm{D}$ (pale purplish pink), 6 preparations can not be stained and 12 preparations close to color $62 \mathrm{~B}$ (moderate purplish pink).

Gram staining results that use basic fuchsin counterstain and used as a control in this preliminary study can be seen in the picture below.

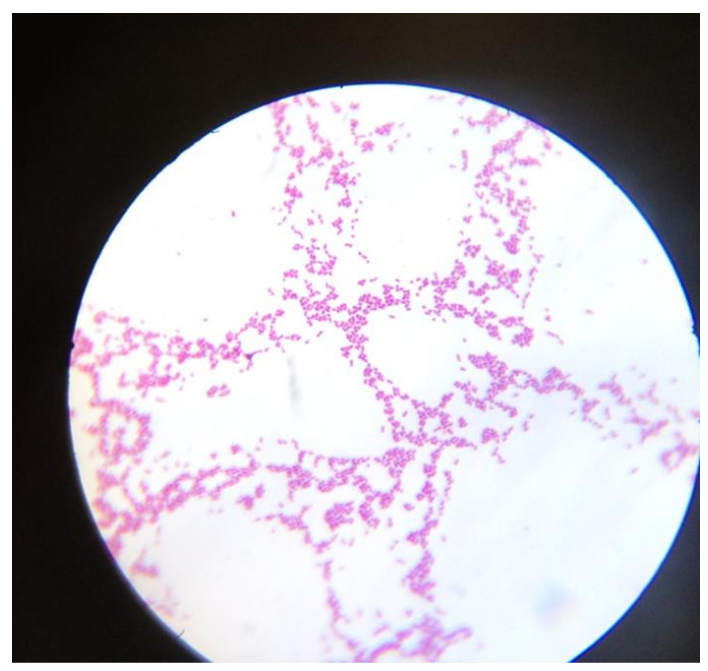

Figure 4. Results of Gram Basic Fuchsin counterstain Closer With Color Code 60C
Gram staining results which use ethyl acetate extract counterstain Red Fruit (Pandanus conoideus Lam.) And the preparations highest yield (12 preparations) as compared to the other can be seen in the picture below.

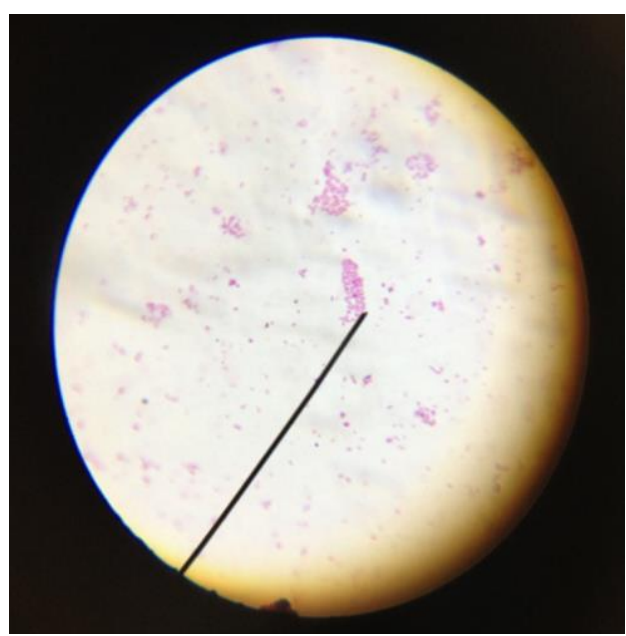

Figure 5. Results of Gram With Ethyl

Acetate Extract counterstain Red Fruit (Pandanus conoideus Lam.) With color code 62B

Results of staining bacteria which use ethyl acetate extract of red fruit that produces the unbright color is closer to the color code 62D (pale purplish pink). 


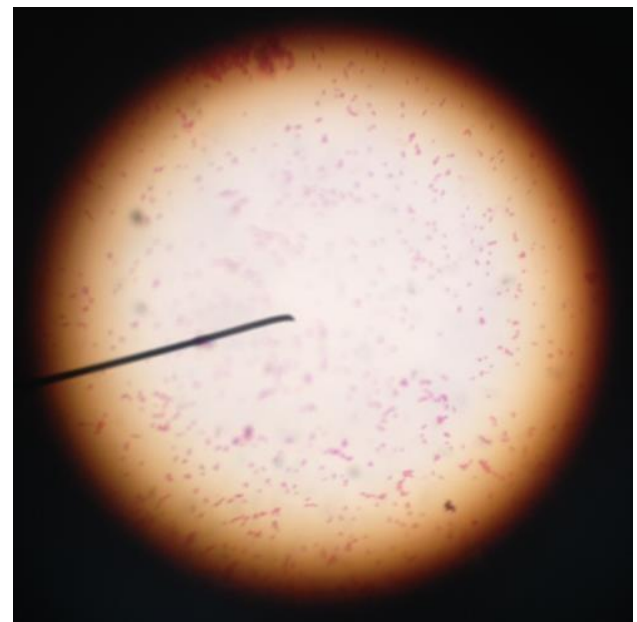

Figure 6. Results of Gram With Ethyl

Acetate Extract counterstain Red Fruit (Pandanus conoideus Lam.) Color Code 62D.

\section{Discussion}

Red fruit in addition to containing nutrients is also active compounds in high enough levels, among others tocopherol, alpha-tocopherol, oleic acid, linoleic acid, and beta-carotene carotenoid. Betacarotene is what causes the red color of the red fruit. This substance has long been exploited by the people of Papua as a good natural food coloring. ${ }^{4.5}$

In this study, the extract of ethyl acetate red fruit, as a counterstain could staining bacteria on Gram staining preparations although the resulting color is not as good as the dye synthetic basic fuchsin, but the purpose of the Gram stain to get an idea of the contrast between Gram + (purple) and Gram- (which is red or pink) is relatively visible.

\section{Reference:}

1. Capuccino, JG \& Sherman, N. 2008. Microbiology; a laboratory manual, $8^{\text {th }}$ ed person- Benjamin Cumming; Pp15-19.

2. Johnson, RT \& Case, CL. 2007. Laboratory experiment in microbiology publishing person Education Inc, San Francisco CA; Pp 3, 25,35

3. Priyono SH. 2008. Consideration of red fruit conservation through plant tissue culture, extraction, fractionation of antioxidant test and anti-diabetic test. Journal of Environmental Technology. 9 (3), 227-234.

4. Budi IM, Paimin FR. 2005. Red Fruit. The Swadaya spreader. Depok. Page 12-17, 20-26, 43-48.

5. Samaranayake L, L. 2006. Essential Microbiology for Dentistry. $3^{\text {th }}$ ed Churchill Livingstone; L Sevier. pp 711, 103-142.

6. Http://www.buahmerah.org/wpcontent/uploads/2016/03/Buah-Merah-Papua-.jpg

7. http://www.google.com/images, your color royal society horticultural 2010. 